\title{
Erratum to: Gene expression profiling in the submandibular gland, stomach, and duodenum of CAVI-deficient mice
}

\author{
Pei-wen Pan • Katri Käyrä · Jukka Leinonen • \\ Marja Nissinen • Seppo Parkkila • \\ Hannu Rajaniemi
}

Published online: 16 February 2011

(C) Springer Science+Business Media B.V. 2011

\section{Erratum to: Transgenic Res \\ DOI 10.1007/s11248-010-9441-2}

Due to an update of the Car6 gene in GenBank ${ }^{\circledR}$, the number of exons in Fig. 1A of the above mentioned publication have been changed from 7 to 8 . Furthermore, the text describing the construction of Car6 targeting vector should be corrected accordingly. The correct representation of Fig. 1 and the concerning paragraph are published on the following page and should be treated as definitive by the reader.

The online version of the original article can be found under doi:10.1007/s11248-010-9441-2.

P. Pan $(\bowtie) \cdot$ S. Parkkila

Institute of Medical Technology, University of Tampere,

Biokatu 6, 33520 Tampere, Finland

e-mail: peiwen.pan@uta.fi

S. Parkkila

School of Medicine, University of Tampere,

Tampere, Finland

P. Pan · S. Parkkila

Centre for Laboratory Medicine, Tampere University

Hospital, University of Tampere, Tampere, Finland

K. Käyrä · J. Leinonen · M. Nissinen · H. Rajaniemi

Department of Anatomy and Cell Biology,

Institute of Biomedicine, University of Oulu,

Oulu, Finland
Within the section 'Construction of Car6 targeting vector' of the 'Materials and methods', the second sentence in the first paragraph should read:

"The vector (pPN2ThGHterm-Car6 targeting vector) was designed such that exons 3 and 4 of the mouse Car6 gene were replaced by the bacterial neomycin resistance gene (Neo)."

The first sentence in the second paragraph must read: "To construct the pPN2ThGHterm-Car6 targeting vector, a short $5^{\prime}$-homologous arm (2,058 bp) containing exon 2 was amplified using the entire mouse Car6 gene clone (described above) as a template."

The fourth sentence in the second paragraph should read: "Subsequently, a long 3'-homologous arm (4,984 bp) containing exons 5 and 6 was amplified using the entire mouse Car6 gene clone as a template."

The correct Fig. 1 and its caption are shown on the following page. 

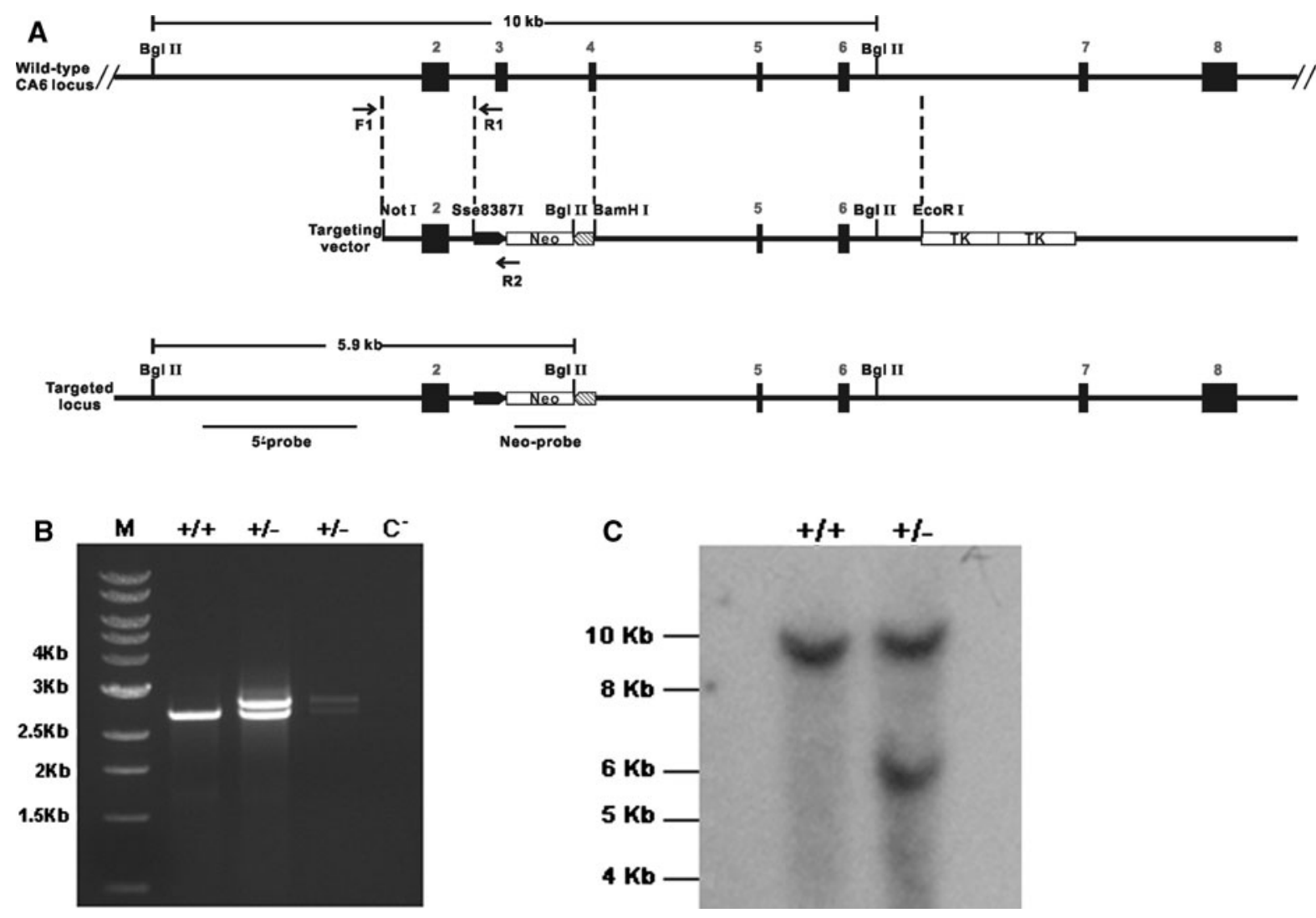

Fig. 1 Targeted disruption of the Car6 gene in ES cells. A A schematic representation of the disruption of the Car6 locus by homologous recombination. Solid boxes represent exons. F1, $\mathrm{R} 1$, and R2 are primers used for genotyping. B Identification of targeted $( \pm)$ ES cell clones using multiplex PCR. M molecular marker. $\mathrm{C}^{-}$indicates the negative control for PCR $\left(\mathrm{H}_{2} \mathrm{O}\right)$. C Characterization of targeted $( \pm)$ ES cell clones by Southern blot 